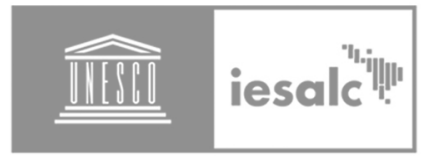

\title{
Unesco
}

Instituto Internacional

para la Educación Superior

en América Latina

y el Caribe
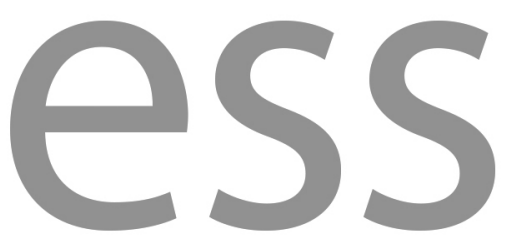

?

Educación

Superior y

Sociedad

Vol. 33 No. 2 (2021)

-

$\bullet$

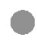

$\bullet$
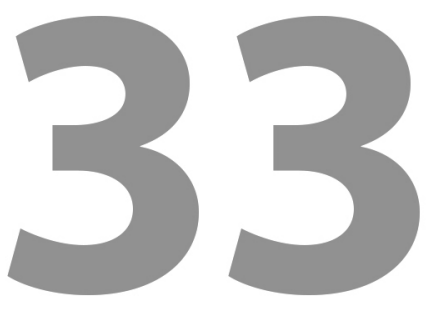

Incluye Dossier Temático:

Desafíos de la educación superior frente a la pandemia de Covid-19 en América Latina y el Caribe 


\section{Educação remota emergencial na formação inicial docente: desafios e possibilidades no contexto da pandemia de COVID-19}

Viviane Potenza Guimarães Pinheiro y Beattriz Guedes de Seixas

\section{RESUMO}

A pandemia de Covid-19 interrompeu as atividades presenciais nos cursos de formação inicial de professores no ensino superior, tornando a educação remota emergencial como uma possibilidade de manter os vínculos entre estudantes e universidades. A partir de estudos sobre formação inicial docente no panorama atual brasileiro, o presente artigo objetiva analisar a migração para a educação remota emergencial de uma disciplina previamente planejada para o modelo presencial em uma universidade pública brasileira, por meio de entrevistas com dezesseis estudantes participantes do curso. A análise, qualitativa e descritiva, das percepções e sentimentos dos licenciandos, sinalizou os desafios enfrentados e as possibilidades de tal experiência. Os resultados apontam como desafios a autonomia requerida pelo contexto, o manejo repentino de ferramentas digitais e a vivência de um cenário complexo, envolvendo demandas profissionais, pessoais e familiares. A comunicação, a organização rápida, a postura da docente e a diversidade de estratégias metodológicas foram ressaltados como potencialidades da disciplina no modelo empregado. Conclui-se que manter os fundamentos da ética, do respeito e da autonomia na formação dos futuros professores, bem como considerar a complexidade do contexto de pandemia por meio de um processo formativo humanizado, foram chaves para oferecer um curso que atendesse às necessidades educacionais contemporâneas.

Palavras-chave: Educação Remota Emergencial; Formação de Professores; Ensino Superior; Covid-19.

\section{Emergency remote teaching in initial teacher training: challenges and possibilities in the context of the Covid-19 pandemic}

\section{ABSTRACT}

The Covid-19 pandemic interrupted face-to-face activities in initial teacher training courses in higher education, with emergency remote teaching as a 
possibility for links between students and universities. Based on studies on initial teacher training in the current Brazilian scenario, this article aims to analyze the migration to emergency remote teaching of a previously planned discipline for the face-to-face model at a Brazilian public university, through interviews with sixteen students participating in the program. The qualitative and descriptive analysis of the graduates' perceptions and feelings signaled the challenges faced and the possibilities of such an experience. The results point out as challenges the autonomy required by the context, the sudden handling of digital tools and the experience of a complex scenario, involving professional, personal and family demands. Communication, fast organization, the teacher's posture and the diversity of methodological strategies were highlighted as potentialities of the discipline in the model that was employed. We concluded that maintaining the fundamentals of ethics, respect and autonomy in the teachers training, as well as considering the complexity of the pandemic context through a humanized training process were keys to offering a course that supplies contemporary teaching needs.

Keywords: Emergency Remote Teaching; Teacher Training; Higher Education; Covid-19.

\section{Enseñanza remota de emergencia en la formación inicial del profesorado: retos y posibilidades en el contexto de la pandemia de Covid-19}

\section{RESUMEN}

La pandemia de Covid-19 interrumpió las actividades presenciales de los cursos de formación inicial del profesorado en educación superior, apareciendo enseñanza remota de emergencia como una posibilidad de creación de vínculos entre estudiantes y universidades. A partir de estudios sobre la formación inicial docente en el escenario brasileño actual, este artículo tiene como objetivo analizar la migración a la enseñanza remota de una disciplina previamente planificada para el modelo presencial en una universidad pública brasileña, a través de entrevistas realizadas a dieciséis estudiantes participantes del programa. El análisis cualitativo y descriptivo de las percepciones y sentimientos de los egresados, señaló los desafíos enfrentados y las posibilidades de tal experiencia. Los resul- 
tados señalan como desafíos la autonomía que requiere el contexto, el manejo repentino de las herramientas digitales y la vivencia de un escenario complejo que involucra exigencias profesionales, personales y familiares. La comunicación, la ágil organización, la postura del docente y la diversidad de estrategias metodológicas se destacaron como potencialidades de la disciplina en el modelo empleado. Concluimos que mantener los fundamentos de la ética, el respeto y la autonomía en la formación de futuros docentes, así como considerar la complejidad del contexto pandémico a través de un proceso de formación humanizado; fueron claves para ofrecer un curso que respondiera a las necesidades educativas contemporáneas.

Palabras clave: Enseñanza Remota de Emergencia, Formación Docente, Educación Superior, Covid-19.

\section{Enseignement à distance en situation d'urgence dans la formation initiale des enseignants: défis et possibilités dans le contexte de la pandémie de Covid-19}

\section{RESUMÉ}

La pandémie de Covid-19 a interrompu les activités présentielles des cours de formation initiale des enseignants dans l'enseignement supérieur, avec l'émergence de l'enseignement à distance en situation d'urgence comme une possibilité de création de liens entre les étudiants et les universités. Basé sur des études sur la formation initiale des enseignants dans le scénario brésilien actuel, cet article vise à analyser la migration vers l'enseignement à distance en situation d'urgence d'une discipline précédemment planifiée pour le modèle présentiel dans une université publique brésilienne, à partir des entretiens réalisés à seize étudiants participants au programme. L'analyse qualitative et descriptive des perceptions et sentiments des diplômés a mis en évidence les défis rencontrés et les possibilités d'une telle expérience. Les résultats pointent en tant que défis l'autonomie requise par le contexte, la gestion soudaine des outils numériques et l'expérience d'un scénario complexe, impliquant des exigences professionnelles, personnelles et familiales. La communication, l'organisation rapide, la posture de l'enseignant et la diversité des stratégies méthodologiques ont été mises en avant comme des potentialités de la discipline du modèle utilisé. Nous 
concluons que le maintien des fondamentaux comme l'éthique, le respect et l'autonomie dans la formation des futurs enseignants, ainsi que la prise en compte de la complexité du contexte de pandémie à travers un processus de formation humanisé étaient essentiels pour offrir un cours répondant aux besoins éducatifs contemporains.

Mots clés: Enseignement à Distance en Situation d'Urgence, Formation des Enseignants, Enseignement Supérieur, Covid-19.

\section{INTRODUÇÃO}

Os cursos de formação docente no ensino superior têm enfrentado desafios, dentre os quais o de oferecer uma formação profissional que atenda à multiplicidade de demandas emergentes no contexto educacional nos últimos tempos. A busca de mudanças na formação inicial de professores tornou-se premente diante das aceleradas e constantes modificações sociopolíticas, culturais, econômicas e tecnológicas, que impactam a produção de conhecimento, bem como as habilidades e competências exigidas das novas gerações para a inserção no mundo do trabalho e para o pleno exercício da cidadania.

No Brasil, embora tais necessidades tenham mobilizado atualizações nos cursos de formação inicial de professores, por força de marcos legais (Brasil, 2015), as alterações, concentradas na reorganização das matrizes curriculares dos cursos de licenciatura, não chegaram a oferecer mudanças significativas em seu modelo formativo (Azevedo et. al., 2012). Considera-se, assim, que o discurso mudou, mas não se alteraram as práticas (Nóvoa, 2011), como apontam pesquisas sobre os cursos de formação de professores em nível superior em nosso país (Pimenta et. al., 2017; Gatti, 2010).

Gatti (2010) ressalta a preocupação com a formação inicial de professores no Brasil, em vista da complexidade dos contextos educacionais na atualidade. Tal preocupação não significa reputar apenas ao professor e à sua formação a responsabilidade pelas graves questões pelas quais passa a educação brasileira, mas chamar a atenção para a importância da formação inicial docente (Gatti, 2010, p. 1360). De acordo com a autora, os cursos de formação necessitam de uma verdadeira revolução, a partir da integração curricular norteada pela função própria da escolarização:"ensinar às novas gerações o conhecimento acumulado 
e consolidar valores e práticas coerentes com nossa vida civil" (Gatti, 2010, p. 1375). Dessa forma, urge uma formação de professores que integre teoria e prática, ultrapassando a lógica fragmentada do conhecimento para a constituição de identidades docentes, que articulem saberes científicos, sociais, culturais e pessoais, com atuação focada na formação do coletivo e nas necessidades das sociedades democráticas (Imbernón, 2006).

A preocupação a respeito da formação inicial docente no ensino superior ganha novos contornos com o advento da pandemia do novo coronavírus, em meados de março de 2020. Em um cenário com a presença cada vez maior de cursos à distância na formação inicial dos professores (Sommer, 2010), os debates no Brasil renovaram-se sobre a pertinência da modalidade da educação à distância (EaD), gerando novas reflexões e diferentes proposições para a continuidade dos cursos que haviam sido elaborados para o modelo presencial ou semipresencial.

O ensino à distância em nível superior é reconhecido pela legislação brasileira (Brasil, 1996). Com a interrupção abrupta da realização de cursos presenciais, foi autorizada pelo Ministério da Educação (Brasil, 2020), a substituição das aulas presenciais por aulas em meios digitais, enquanto durar a situação de pandemia. Tal medida visou minimizar o prejuízo na aprendizagem, buscando manter o calendário letivo das instituições de ensino superior.

Essa situação de excepcionalidade, no entanto, não pode ser enquadrada como educação à distância, uma vez que tal modalidade não apenas propicia processos de ensino e aprendizagem por meio de tecnologias de informação e comunicação, mas requer formação específica de profissionais, além de políticas de acesso e de instrumentos adequados e planejados para as condições de aprendizagem dos estudantes (Arruda, 2020). Em seu lugar, tem sido adotado o conceito de ensino remoto emergencial (ERE), que consiste em uma mudança temporária no modelo educacional que anteriormente era realizado presencialmente ou de forma híbrida e que retornará ao seu formato anterior assim que a situação de crise estiver terminada (Hodges et. al, 2020).

Importante destacar que o conceito defendido por Hodges et. al. (2020) é ensino remoto emergencial, reportando-se aos atos e práticas dos professores, como responsáveis por elaborar as estratégias e organização dos cursos em novo formato. Em nosso estudo, preferimos utilizar o termo "educação remota emergencial" para evidenciar que, embora o papel do educador seja central, a educação envolve um processo formativo mais amplo e não apenas instrucional, 
compreendendo a dimensão ética de aprender a ser e a conviver no mundo (Delors et. al.1996).

Para Hodges et. al. (2020), o principal objetivo da ERE, diferentemente da EaD, não é criar um ecossistema educacional robusto, mas providenciar acesso temporário e suporte de forma rápida e que garanta minimamente a continuidade no processo de ensino e aprendizagem. Assim, a ERE assume o importante princípio de manter o vínculo entre estudantes, professores e profissionais da educação (Arruda, 2020).

Como sinaliza Arruda (2020), na educação superior brasileira a continuidade das aulas por meio da ERE deu-se em nível micro institucional. As respostas acadêmicas à situação pandêmica foram diversas, levando em consideração as condições de acesso e as possibilidades de continuidade dos cursos. Apesar de um período de suspensão de aulas em algumas instituições, a grande maioria das universidades brasileiras produziu planos de contingenciamento para que o semestre letivo permanecesse em desenvolvimento por meio da mediação tecnológica (Arruda, 2020).

\section{Panorama da migração do modelo presencial para a ERE}

Os cursos de formação docente, com a interrupção das atividades educacionais presenciais, não apenas precisaram proporcionar o acesso tecnológico às aulas e atividades, mas, sobretudo, considerar a complexidade representada por docentes e licenciandos confinados, que se encontravam em frágeis condições emocionais, físicas e sociais de acompanhamento das atividades acadêmicas. A despeito de tal complexidade, as mudanças empreendidas para a continuidade do processo formativo acabaram oferecendo menos suporte aos estudantes e docentes devido ao cenário de preparação rápida, causando estresse e dificuldades de manutenção das atividades (Hodges et. al., 2020). Muitos cursos de formação inicial de professores foram adaptados com os mesmos princípios que ainda balizam o ensino superior, priorizando a transmissão de conhecimentos (Araújo, 2020).

Hodges et. al. (2020) sinalizam que, apesar das dificuldades encontradas, esse cenário pode fazer emergir soluções criativas, de acordo com as necessidades dos envolvidos, oferecendo maior flexibilidade e um processo formativo mais centrado no estudante. Pedró (2020) aponta que a pandemia pode gerar "janelas 
de oportunidades" para o ensino superior. Dentre tais oportunidades estão o aprimoramento das competências docentes e os avanços no planejamento híbrido e no uso com qualidade do meio virtual nos cursos do ensino superior. Concordamos com Araújo (2020) ao indicar a necessidade de adequação do processo educacional ao contexto remoto, e não realizar a ERE como uma transposição do modelo presencial. Assim, concebendo a educação pela ótica das epistemologias construtivista (Piaget, 1979) e da pedagogia relacional (Freire, 1974/2019), torna-se ainda mais urgente oferecer um processo inclusivo e libertador, que reconheça cada ser humano em sua integração com o mundo. A migração de uma disciplina presencial para a ERE, nesse sentido, precisa manter, com estratégias diferentes, os princípios da formação de educadores, no sentido de colaborar para a constituição de identidades docentes comprometidas com a transformação social, por meio do desenvolvimento de competências necessárias à sociedade na atualidade (Imbernón, 2006). É preciso, para Bates (2017), reconhecer quem e como são os alunos universitários hoje, assim como o que é necessário que desenvolvam em sua formação profissional para atender às demandas de nosso século.

Se desejamos formar profissionais da educação com responsabilidade social, é imprescindível que os cursos, também na ERE, fundem-se na ética, no respeito e na autonomia do educando (Freire, 1996). Considerar o licenciando como um ser único e dotado de uma trajetória e conhecimentos que precisam ser respeitados, leva a fomentar uma verdadeira cultura participativa, mesmo à distância, na qual estudantes e docentes trabalham em conjunto para construir cada vez mais conhecimentos, numa lógica ecológica, que se adapta e evolui consoante os interesses daqueles que o integram. Esse entendimento mútuo requer relacionamentos fortes e contínuos entre docentes e discentes, a fim de que "aprendam a fazer uma leitura sensível uns dos outros com o passar do tempo" (Hargreaves, 2003, p. 133). Dessa forma, faz-se possível levar os futuros educadores a se assumirem, nas palavras de Freire (1996), como sujeitos produtores do saber, que impactam a formação das novas gerações para a construção de uma sociedade mais justa e solidária.

Para Araújo (2020), no contexto de pandemia e no pós-pandemia, o caminho está nas metodologias ativas de aprendizagem, no uso de diferentes linguagens e na valorização de cada estudante, em projetos pautados em conteúdos contextualizados nas suas vidas. As atividades da ERE precisam priorizar a colabora- 
ção e a personalização, promovendo engajamento e a construção da autonomia discente. Além disso, é necessário entender que mobilizam não apenas esforço e domínio técnico e intelectual, mas questões emocionais inerentes à vasta rede de relacionamentos humanos importantes e significativos ao contexto formativo (Hargreaves, 2003).

Em vista das dificuldades e possibilidades características do panorama descrito, o presente artigo tem como objetivo apresentar resultados da mudança para a ERE de uma disciplina de formação inicial de professores previamente planejada para o modelo presencial em uma universidade pública de São Paulo, Brasil, no contexto da pandemia de Covid-19. A partir dos dados coletados com os estudantes, por meio de entrevistas ao longo do curso, pretendeu-se analisar percepções e sentimentos que as mudanças empreendidas engendraram, sinalizando os desafios enfrentados e as "janelas de oportunidades" trazidas por tal experiência.

\section{Contexto da disciplina}

A disciplina "Psicologia da Educação, Desenvolvimento e Práticas Escolares" é ministrada na Faculdade de Educação para estudantes de diversos cursos de licenciatura da Universidade de São Paulo. Trata-se de uma disciplina de fundamentos teóricos da área da psicologia que almeja contribuir para a atuação de professores na educação básica, articulando a reflexão e a problematização, à luz de teorias psicológicas, de perspectivas do desenvolvimento, da aprendizagem, das relações interpessoais, dos valores e da constituição identitária, às possibilidades de construção de uma escola que atenda às necessidades do mundo atual.

A disciplina é organizada semestralmente, com 15 encontros semanais presenciais de 4 horas. Ela conta com o estágio supervisionado de 30 horas, em que os licenciandos precisam investigar sobre as temáticas abordadas no curso, preferencialmente em escolas públicas de educação básica.

A metodologia utilizada no curso centra-se no estudante, procurando proporcionar engajamento e participação nas atividades propostas. O curso presencial divide-se em aulas teóricas, realizadas de forma interativa, com o uso de metodologias ativas, e no trabalho colaborativo. Os instrumentos avaliativos são diversos e processuais, incluindo trabalhos em grupo, individuais e autoavaliação. 
A disciplina iniciou-se presencialmente, com 43 estudantes matriculados, no dia 19 de fevereiro de 2020 . Os estudantes, majoritariamente jovens (63\% entre 19 e 29 anos) e do sexo feminino ( $77 \%$ dos estudantes), eram oriundos de diversos cursos de licenciatura da universidade. Estavam, em sua maioria, no último ano da graduação ( $68 \%$ dos participantes) e possuíam boas condições de acesso à internet (65\% dos participantes). $35 \%$ dos estudantes tiveram Covid19 ou contato com pessoa infectada no período.

Desde o início da disciplina, foi disponibilizado um ambiente virtual na plataforma Google Classroom. O uso da tecnologia na disciplina pretendia-se híbrido, para exploração do conteúdo previamente e de acordo com o percurso de cada estudante, para consolidar bases para o trabalho colaborativo e para suporte ao processo formativo.

A disciplina foi interrompida na terceira semana de março por força do decreto estadual que solicitava a suspensão total das atividades presenciais em universidades. A mudança da disciplina para o modelo de educação remota emergencial foi realizada de forma rápida pela professora e monitores. Os primeiros passos dessa reestruturação foram a criação de um grupo de whattsapp, para aproximação entre docente, monitores e discentes, e o envio de um formulário para compreensão sobre os estudantes e suas condições de saúde e de acesso à tecnologia.

A docente encaminhou o novo programa e também expôs no ambiente virtual o panorama da universidade em relação à continuidade das atividades à distância, solicitando aos discentes que se posicionassem a respeito da manutenção ou não da disciplina no modelo remoto. Tendo o aceite de todos os estudantes que compareceram nas três primeiras aulas, o curso recomeçou, no novo formato, no dia 26 de março.

As mudanças para o modelo remoto emergencial procuraram atender à complexidade da situação pandêmica e as possibilidades das atividades online, levando em consideração o acolhimento aos estudantes e as questões emocionais que perpassam o processo educacional. O cenário exigiu um novo domínio e exploração de ferramentas digitais que facilitassem a organização das informações, a construção de conhecimentos e a interação, mantendo os fundamentos éticos que estabelecem o reconhecimento de cada aluno em sua humanidade e a responsabilidade por uma formação que lhe possibilite compreender o mundo e como deseja habitá-lo (Puig, 2007). Para atender as demandas desse 
contexto, as temáticas do curso foram distribuídas em roteiros, nos quais constavam os materiais, as atividades síncronas e assíncronas e os prazos de realização. Tornou-se necessário replanejar as atividades de estágio e o processo avaliativo. Com a impossibilidade de realizar os estágios presencialmente nas escolas, a proposta foi a realização de uma atividade em grupo a partir de entrevistas com educadores, que possibilitou a articulação de diversos temas e conceitos trabalhados nas aulas. A atividade foi dividida em três etapas: 1) Entrevista com professores sobre seus projetos de vida, seguindo um roteiro prévio elaborado pela docente; 2) Análise das entrevistas em grupo, através de encontros síncronos no Google Meet; 3) Sistematização e produção de relatório em grupo, que deveria conter os conceitos teóricos que deram suporte às análises, os procedimentos metodológicos, a análise e discussão dos dados e as considerações finais, incluindo as descobertas do grupo, indicações para a formação de professores e intervenções educacionais.

Tal proposta possibilitou que os grupos se inserissem no contexto educacional, principalmente na vida dos educadores, tanto nas suas experiências quanto nos seus projetos futuros e investigassem de que maneira as condutas individuais intelectuais, afetivas e éticas se relacionam às práticas docentes (Araújo, Arantes, \& Pinheiro, 2020). A docente e os monitores auxiliaram os grupos em todas as etapas, movimento que aproximou todos os envolvidos, levando o grupo a se tornar uma comunidade de aprendizagem (Imbernón, 2006).

O processo de escuta e acolhimento dos estudantes foi importante para adequar o curso às suas necessidades. Após duas semanas, a preocupação com a evasão do curso levou a docente e os monitores a ouvir os alunos através de um formulário de sugestões. As respostas dos alunos levaram a equipe a repensar e alterar algumas das propostas planejadas, como aumentar o número de encontros síncronos, criar uma planilha organizadora das atividades e informações, elaborar vídeos tutoriais e também flexibilizar prazos de entregas dos instrumentos avaliativos. Além desse formulário, outros momentos dos encontros síncronos foram destinados a ouvir os estudantes e a repensar coletivamente o programa da disciplina.

Finalizaram a disciplina 40 estudantes, sendo 39 aprovados, um reprovado e três desistentes. 


\section{METODOLOGIA DA PESQUISA}

A presente pesquisa e seu objetivo de compreender, por meio das perspectivas e dos sentimentos dos estudantes, os desafios e as possibilidades da migração da disciplina para a ERE, foram apresentados aos alunos em um dos encontros síncronos. Na ocasião, foi feito o convite para a participação e envio de formulário, com o Termo de Consentimento Livre e Esclarecido e perguntas para contextualização dos participantes. Os monitores da disciplina entraram em contato com os estudantes que se voluntariaram para participar da pesquisa e combinaram os dias e horários das três breves entrevistas, realizadas por meio da plataforma de preferência do entrevistado, Whatsapp ou Google Meet. Foram seguidos os procedimentos éticos de pesquisa, de acordo com a Resolução $n^{\circ}$ 466/ 2012, que regula e orienta as investigações com seres humanos no Brasil. A pesquisa configura-se como qualitativa e descritiva. Para coletar os dados com os estudantes, foram realizadas entrevistas em três fases.

Fase 1: momento de migração para a ERE;

Fase 2: desenvolvimento da disciplina na ERE;

Fase 3: após o término da disciplina.

Os roteiros, previamente elaborados pelos autores, continham questões que versavam sobre as percepções e sentimentos dos estudantes a respeito da disciplina no modelo remoto emergencial, considerando o contexto do estudante e da universidade na pandemia. A entrevista foi aplicada de forma semi-estruturada (Marconi, \& Lakatos, 2004).

Ao todo, participaram desta pesquisa 16 licenciados, representando $40 \%$ do total de estudantes matriculados na disciplina. Doze eram do sexo feminino e 4 do sexo masculino. Treze participantes estavam na faixa etária de 20 a 28 anos e três entre 35 e 49 anos.

Grande parte declarou ter dispositivo tecnológico para realizar as atividades remotas (14 participantes) e os demais ( 2 participantes) indicaram que dividem o dispositivo tecnológico com outras pessoas. A maioria deles afirmar ter boas condições em seu domicílio para fazê-las (9 participantes), incluindo espaço e privacidade, enquanto 4 participantes apontaram que as condições são regulares. O acesso à internet foi considerado bom para 11 participantes e regular para 5. 
Em relação às questões de saúde, seis estudantes relataram terem contraído ou terem tido contato com uma pessoa próxima que contraiu Covid-19.

As respostas obtidas foram analisadas a partir da análise de conteúdo (Bardin, 2011). Realizadas as entrevistas, foi feita a transcrição do material coletado e realizados os procedimentos de pré-análise, exploração e tratamento dos resultados. A etapa de pré-análise contou com a leitura flutuante dos dados transcritos e foi seguida pela formulação de categorias. As categorias surgiram a partir dos temas que se repetiam com muita frequência, sendo recortados para comparação.

\section{Perspectivas e sentimentos dos licenciandos na ERE}

A partir da análise do conteúdo das entrevistas, foram destacadas as categorias e os temas mais frequentes, com exemplos de falas dos participantes que permitem vislumbrar suas concepções e sentimentos na migração e desenvolvimento da disciplina na ERE.

\section{Primeira fase}

Na primeira fase de entrevistas, os licenciandos foram indagados a respeito do início da disciplina na ERE. Perguntou-se a eles sobre sua opção de continuidade, pensamentos e sentimentos no momento, dificuldades e facilidades no processo e suas impressões iniciais sobre a educação à distância. Foram destacadas quatro categorias do conteúdo das respostas.

A categoria Particularidades da disciplina aborda os aspectos que chamaram a atenção dos participantes na migração da disciplina para a ERE, fazendo comparação com outras disciplinas que já cursaram ou que estavam cursando no momento. Os participantes evidenciaram que, nessa disciplina, encontraram acolhimento, diálogo e compreensão no tratamento da docente com a turma, bem como significaram positivamente a organização do cronograma e dos materiais disponibilizados.

A categoria Desafios da Educação Remota Emergencial aborda as indicações dos participantes sobre as características mais desafiadoras desse modelo para os estudantes, tais como a falta de socialização proporcionada por encontros presenciais, a ausência de uma divisão entre o espaço acadêmico, pessoal e profissional, a dificuldade em se organizar no momento da migração, considerando a necessidade de recursos como computador e internet, e a necessidade de aprender a utilizar as ferramentas digitais até então desconhecidas. 


\section{Quadro 2. Temas e exemplos da categoria Particularidades da disciplina}

\begin{tabular}{|c|c|}
\hline TEMAS & EXEMPLOS \\
\hline $\begin{array}{l}\text { Comparação } \\
\text { com outras } \\
\text { disciplinas } \\
(\mathrm{n}=11 ; 68,75 \%)\end{array}$ & $\begin{array}{l}\text { H0,22 anos, masc:"[...] muitos [professores] deixaram só ensaios e textos, "leiam e respondam o questionário". } \\
\text { Enão éa mesma coisa, é preciso o diálogo da professora, é preciso a aula, é preciso ter tudo isso [...]" } \\
\text { IA, } 44 \text { anos, fem: "[...] Eu nunca tinha participado através do Google Meet de uma aula, eu cheguei até } \\
\text { a fazer a matéria de libras [...]e era só assim assistir os vídeos, estudar sozinho, gravar via youtube e } \\
\text { mandar de volta, não tinha interação como a gente teve em Psicologia da Educação com o Google Meet." }\end{array}$ \\
\hline $\begin{array}{l}\text { Postura da } \\
\text { docente } \\
\text { responsável } \\
(\mathrm{n}=7 ; 43,75 \%)\end{array}$ & $\begin{array}{l}\text { AD, } 23 \text { anos, fem: "[...] A professora também sempre está presente, sempre respondendo as nossas } \\
\text { dúvidas, conversando com a gente no grupo, mandando novas coisas, perguntando como a gente está. } \\
\text { [...] eu acho que em Psicologia da educação foi muito pensado o nosso lado e o lado do professor também, } \\
\text { porque é desumano pensar que alguém conseguiria resolver todas as coisas desse jeito." }\end{array}$ \\
\hline $\begin{array}{l}\text { Organização } \\
\text { desta disciplina } \\
(n=8 ; 50 \%)\end{array}$ & $\begin{array}{l}\text { CL, } 35 \text { anos, fem: "[...] quando eu consegui achar, entrar no Google Sala de Aula, eu já consegui ver } \\
\text { todos os explicações de como seria, a disciplina do novo programa, a organização das aulas, como tinham } \\
\text { que ser, é... [...] tudo isso já tava explicado, então isso ajudou bastante pra mim, pra eu poder decidir se } \\
\text { eu podia fazer ou não [...]" } \\
\text { MB, } 23 \text { anos, fem: "[...] tudo foi muito bem organizado e foi tudo muito bem conversado, então quando } \\
\text { ia ter uma atividade ou uma aula, o que fosse, né, o contato pelo grupo do WhatsApp era sempre bastante } \\
\text { efetivo [...]" }\end{array}$ \\
\hline \multicolumn{2}{|l|}{ Fonte: As autoras } \\
\hline & $\begin{array}{l}\text { Para além da disciplina em foco, a categoria Percepções advindas do contexto } \\
\text { traz questões relativas à economia de tempo por não se deslocar para a univer- } \\
\text { sidade, à exigência de autonomia acadêmica e a situação de outros estudantes } \\
\text { universitários que não possuem computador e acesso à internet em casa. } \\
\text { A categoria Sentimentos relatados evidencia um sentimento de conforto para } \\
\text { participar das aulas virtuais, alegando que o formato diminuía a tensão, vergonha } \\
\text { e timidez. A preocupação em atrasar o fim da graduação foi um sentimento } \\
\text { muito frequente entre os alunos, que os motivou para continuar na disciplina } \\
\text { no formato não presencial. As impressões prévias que os estudantes tinham } \\
\text { sobre o modelo EaD, de um modo geral, geraram desconfianças e inseguranças. }\end{array}$ \\
\hline
\end{tabular}




\section{Quadro 3. Temas e exemplos da categoria Desafios da Educação Remota Emergencial}

\begin{tabular}{|c|c|}
\hline TEMAS & EXEMPLOS \\
\hline $\begin{array}{l}\text { Socialização } \\
\text { prejudicada } \\
(n=7 ; 43,75 \%)\end{array}$ & $\begin{array}{l}\text { AL, } 23 \text { anos, masc: "[...] acho que o sentimento que fica maior é de solidão e essa coisa de... De, às vezes, } \\
\text { por exemplo, eu tive um encontro virtual, né, às vezes, e as pessoas não aparecem, né - como não aparece } \\
\text { o rosto das pessoas, só aparece a letra inicial do nome delas na tela [...]" } \\
\text { MC, } 21 \text { anos, fem: "[...] a gente acaba ficando, ahn... Um pouco agoniado, um pouco triste de ficar em } \\
\text { casa, de não poder sair, de não poder ter as aulas práticas, têm essas trocas mais pessoalmente que, às } \\
\text { vezes, é um pouco mais enriquecedora [...]" }\end{array}$ \\
\hline $\begin{array}{l}\text { Casa, familia } \\
\text { equestões } \\
\text { de espaço } \\
(n=3 ; 18,75 \%)\end{array}$ & $\begin{array}{l}\text { H0, } 22 \text { anos, masc: "[...] eu ainda acho difícil a experiência do ensino em alguns dias, principalmente } 0 \\
\text { fato de não serem espaços separados, eu sempre achei muito importante que os espaços separados de } \\
\text { trabalho, estudo, ensino e familiares foram campos separados. [...." }\end{array}$ \\
\hline $\begin{array}{l}\text { Dificuldade } \\
\text { de se organizar } \\
\text { no começo } \\
(\mathrm{n}=8 ; 50 \%)\end{array}$ & $\begin{array}{l}\text { CL, } 35 \text { anos, fem:"De início, eu não consegui participar - demorou algumas semanas para eu conseguir } \\
\text { me organizar aqui na minha casa, com meus afazeres, com a dinâmica do computador também porque } \\
\text { eu tava... Meu computador tava quebrado[...]" } \\
\text { MC, } 21 \text { anos, fem: "[...] no começo foi difícil pra mim, eu acho que uma dificuldade que eu tive, bem } \\
\text { forte, foi na plataforma, porque eu ia perdendo, a... As informações lá, os textos, os links [...]" }\end{array}$ \\
\hline $\begin{array}{l}\text { Aprender a usar } \\
\text { ferramentas } \\
\text { digitais } \\
(\mathrm{n}=4 ; 25 \%)\end{array}$ & $\begin{array}{l}\text { BB, } 28 \text { anos, masc: "[...] Então, a princípio, foi bem perdidão mesmo, eu fiquei bem perdidão, tipo "ok, } \\
\text { que que eu faço agora? Só assisto aula? Que que eu faço, onde que vou assistir a aula", sabe? Que que eu } \\
\text { vou fazer, e que que eu vou precisar ter comigo de app?", aí foi onde eu baixei, no meu celular, o Google } \\
\text { Meet, baixei Google Zoom, baixei o Classroom, baixei vários apps que a gente tá usando ao longo disso, né } \\
\text { [...]" }\end{array}$ \\
\hline Fonte: As autoras & $\begin{array}{l}\text { Segunda fase } \\
\text { A segunda fase de entrevistas abordou o desenvolvimento da disciplina, ques- } \\
\text { tionando os estudantes a respeito das atividades que mais Ihes proporcionaram } \\
\text { aprendizagens, quais eram seus pensamentos e sentimentos durante o curso, } \\
\text { bem como motivações para continuar na disciplina. Três categorias destacam- } \\
\text { se nas respostas dos licenciandos. }\end{array}$ \\
\hline
\end{tabular}




\section{Quadro 4. Temas e exemplos da categoria Percepções advindas do contexto}

\begin{tabular}{|c|c|}
\hline TEMAS & EXEMPLOS \\
\hline $\begin{array}{l}\text { Ganho de tempo } \\
\text { por não haver } \\
\text { deslocamento } \\
(n=3 ; 18,75 \%)\end{array}$ & $\begin{array}{l}\text { "AD, } 23 \text { anos, fem: "Eu acho que o fato de não precisar acordar } 6 \text { horas da manhã e pegar o ônibus } \\
\text { lotado para chegar na USP já ajudou bastante. Nesse quesito me ajudou muito. [...]" } \\
\text { IL, } 20 \text { anos, fem: "[...] eu me adapto muito melhor ao ensino à distância do que ao presencial, até } \\
\text { porque eu gastava quase } 5 \text { horas, na verdade um pouquinho mais de } 5 \text { horas indo e voltando da faculdade } \\
{[\text {...." }}\end{array}$ \\
\hline $\begin{array}{l}\text { Necessidade } \\
\text { de autonomia e } \\
\text { autorregulação } \\
(n=7 ; 43,75 \%)\end{array}$ & $\begin{array}{l}\text { BB, } 28 \text { anos, masc: "[...] caiu minha ficha que eu dependia muito do professor: também que eu dependia } \\
\text { muito do que o professor falava em aula para... Ou cobrava, e dos prazos que ele dava para me começar a } \\
\text { me mexer e fazer as coisas certas, sabe? E eu entendi que no EaD eu ia ter que ter mais iniciativa, mesmo } \\
\text { vocês dando todo esse suporte, dando todo esse auxílio na gente [...]" } \\
\text { IL, } 20 \text { anos, fem: "[...] talvez o EaD ele exija, talvez não, com certeza, exige uma autonomia muito maior } \\
\text { do que o ensino tradicional porque você precisa, o professor não tá lá no seu lado toda hora, então você } \\
\text { precisa ter essa maturidade mais desenvolvida para você conseguir se firmar nesse compromisso de } \\
\text { estudar tudo na hora certa [...]" }\end{array}$ \\
\hline $\begin{array}{l}\text { Menção às } \\
\text { pessoas } \\
\text { sem acesso } \\
(n=3 ; 18,75 \%)\end{array}$ & $\begin{array}{l}\text { NI, } 20 \text { anos, fem: "[...] Só que daí também veio outra coisa para gente, que é pensar não só na gente, } \\
\text { que tem condições de acessar uma internet, de poder acompanhar as aulas, mas a gente precisava pensar } \\
\text { também, nesse momento, nas pessoas que não teriam essa possibilidade [...]" }\end{array}$ \\
\hline Fonte: As autoras & $\begin{array}{l}\text { Na categoria Particularidades da disciplina, os estudantes evidenciaram os as- } \\
\text { pectos que Ihes chamaram atenção no desenvolvimento da disciplina na ERE, } \\
\text { estabelecendo comparações com as outras disciplinas cursadas concomitante- } \\
\text { mente. O acolhimento, carisma e flexibilidade proporcionados pela docente } \\
\text { responsável foram muito significativos, assim como o planejamento do curso, } \\
\text { os diálogos estabelecidos, a clareza do programa e a facilidade de encontrar os } \\
\text { materiais. A possibilidade de interagir com os outros alunos da turma e o apren- } \\
\text { dizado proporcionado pelas discussões, incidindo na compreensão sobre si } \\
\text { mesmos em relação ao outro e ao mundo, foram bastante mencionados. Indi- } \\
\text { caram, ainda, a correspondência entre o que estudaram na graduação sobre } \\
\text { EaD e o que estava sendo realizado ao longo do curso. }\end{array}$ \\
\hline
\end{tabular}




\section{Quadro 5. Temas e exemplos da categoria Sentimentos relatados}

\begin{abstract}
TEMAS EXEMPLOS
Maior conforto

para falar nas

aulas online

$(n=2 ; 12,5 \%)$
\end{abstract}

Preocupação em

atrasar o fim da

graduação

$(n=8 ; 50 \%)$

Desconfianças

prévias com rela-

ção ao EaD

$(n=3 ; 18,75 \%)$

Fonte: As autoras

Na categoria Desafios da ERE, foram apontados os desafios experienciados ao longo do desenvolvimento do curso no formato remoto: a ausência de uma divisão entre o espaço acadêmico, pessoal e profissional, a dificuldade em se organizar no momento da transposição do curso, a necessidade de aprender a utilizar as ferramentas digitais até então desconhecidas e de desenvolver autonomia diante das atividades e dos prazos envolvidos.

A categoria Sentimentos relatados apresenta a valorização do conteúdo abordado nas aulas e pelas diversas metodologias adotadas. A preocupação em atrasar o fim da graduação motivou os alunos a continuarem na disciplina. A dedicação da docente responsável e dos monitores da disciplina despertaram um sentimento de gratidão e vontade de retribuir o esforço feito. 


\section{Quadro 6. Temas e exemplos da categoria Particularidades da disciplina}

\begin{tabular}{|c|c|}
\hline TEMAS & EXEMPLOS \\
\hline $\begin{array}{l}\text { Comparação com } \\
\text { outras disciplinas } \\
(n=6 ; 37,5 \%)\end{array}$ & $\begin{array}{l}\text { H0, } 22 \text { anos, masc: "[...] em comparação com outros professores que eu encontrei na graduação e na li- } \\
\text { cenciatura os quais eu não vou citar nomes pra não ser antiético, eu sinto que foi, talvez tenha sido a } \\
\text { disciplina mais feliz que eu fiz nesse semestre em termos de organização." }\end{array}$ \\
\hline $\begin{array}{l}\text { Postura da } \\
\text { docente } \\
\text { responsável } \\
(n=6 ; 37,5 \%)\end{array}$ & $\begin{array}{l}\text { IA, } 44 \text { anos, fem: A professora é muito carismática, ela se preocupou muito em ajudar a gente a não } \\
\text { perder o semestre, se prontificou a mexer no cronograma que já tinha sido apresentado em sala de aula, } \\
\text { fez bastante modificação não uma vez, mas foram várias vezes [...]" }\end{array}$ \\
\hline $\begin{array}{l}\text { Organização } \\
\text { desta disciplina } \\
(\mathrm{n}=9 ; 56,25 \%)\end{array}$ & $\begin{array}{l}\text { MB, } 23 \text { anos, fem: "[...] outra coisa que me chamou bastante atenção que eu também já comentei, foi } \\
\text { como o andamento da disciplina, né, como as coisas sempre foram conversadas, como tudo foi planejado } \\
\text { muito... Foi tudo muito deixado às claras, no caso, né, foi tudo sempre muito dialogado, então não } \\
\text { tiveram sobressaltos durante a disciplina e aí isso acabou me motivando a continuar." }\end{array}$ \\
\hline $\begin{array}{l}\text { Experiência } \\
\text { positiva com } \\
\text { a disciplina } \\
(n=5 ; 31,25 \%)\end{array}$ & $\begin{array}{l}\text { GH, } 22 \text { anos, fem: "Eu não tenho experiência com ensino a distância, né, então eu tô tendo uma } \\
\text { experiência bastante positiva nessa matéria. É, não sei como pode melhorar porque, para mim, tá dando } \\
\text { certo, pessoalmente." }\end{array}$ \\
\hline $\begin{array}{l}\text { Possibilidade de } \\
\text { interagir com os } \\
\text { outros alunos } \\
(n=6 ; 37,5 \%)\end{array}$ & $\begin{array}{l}\text { MC, } 21 \text { anos, fem: "[...] quando a gente discute, né, quando a gente vê } 0 \text { olhar de outra pessoa, pra } \\
\text { mim, eu acho que é o momento que eu mais aprendo, né, eu acho que na troca eu aprendo bastante, } \\
\text { então as aulas síncronas foram bem importantes pra mim, eu gostei muito [...]" }\end{array}$ \\
\hline $\begin{array}{l}\text { Adequação às } \\
\text { necessidades e } \\
\text { dificuldades dos } \\
\text { alunos } \\
(\mathrm{n}=7 ; 43,75 \%)\end{array}$ & $\begin{array}{l}\text { JB, } 20 \text { anos, fem: "[...] Acho que no geral a única dificuldade que eu tive foi com relação ao Classroom, } \\
\text { porque eu acho uma plataforma muito confusa, às vezes é difícil de achar as coisas que você quer. Mas } \\
\text { vocês criaram um documento com todos os links e ficou mais fácil." }\end{array}$ \\
\hline $\begin{array}{l}\text { A prática } \\
\text { correspondeu ao } \\
\text { que estudou na } \\
\text { teoria sobre EaD } \\
(\mathrm{n}=2 ; 12,5 \%)\end{array}$ & $\begin{array}{l}\text { H0, } 22 \text { anos, masc: "[...] enquanto eu fui fazendo essa disciplina eu acabei fazendo uma disciplina de } \\
\text { metodologia do ensino de língua estrangeira e para fazer uma atividade eu fui ler um artigo sobre ensino } \\
\text { à distância, ensino remoto e como lidar com ensino remoto, [...], em grande parte a professora encaixa } \\
\text { muitos pontos sugeridos pelos autores." }\end{array}$ \\
\hline
\end{tabular}




\section{Quadro 7. Temas e exemplos da categoria Desafios da ERE}

\begin{tabular}{|c|c|}
\hline TEMAS & EXEMPLOS \\
\hline $\begin{array}{l}\text { Casa, familia e } \\
\text { questões de } \\
\text { espaço } \\
(n=3 ; 18,75 \%)\end{array}$ & $\begin{array}{l}\text { SV, } 26 \text { anos, fem: "Olha a dificuldade foi só questão de estar em casa e aquela doideira da minha filha } \\
\text { correndo, gritando, mas aí às vezes eu tentava dar um jeito [...] Porque aí juntou todo o meu trabalho, } \\
\text { todo mundo perdido sem saber o que fazer, aí deu uma bagunçada." }\end{array}$ \\
\hline $\begin{array}{l}\text { Dificuldade de } \\
\text { se organizar no } \\
\text { começo } \\
(n=2 ; 12,5 \%)\end{array}$ & $\begin{array}{l}\text { IL, } 20 \text { anos, fem: "Foi um pouquinho difíil me acostumar porque tinha o roteiro né, tinha bastante } \\
\text { coisa, [...], mas depois eu consegui me organizar um pouco, foi essa dificuldade eu demorei um pouco } \\
\text { para organizar, mas depois correu tudo bem." }\end{array}$ \\
\hline $\begin{array}{l}\text { Aprender a } \\
\text { usar ferramentas } \\
\text { digitais } \\
(n=6 ; 37,5 \%)\end{array}$ & $\begin{array}{l}\text { BB, } 28 \text { anos, masc:"a parte das dificuldades que eu posso relatar, que eu lembro que tive - foi aprender } \\
\text { a mexer no Google Classroom, aprender a mexer no Google Drive [...]" }\end{array}$ \\
\hline $\begin{array}{l}\text { Necessidade de } \\
\text { autonomia e au- } \\
\text { torregulação } \\
(\mathrm{n}=3 ; 18,75 \%)\end{array}$ & $\begin{array}{l}\text { AD, } 23 \text { anos, fem: "[...] Eu tive que aprender a ter autonomia pra fazer as coisas mesmo. Eu me organizar } \\
\text { com o meu calendário pra eu olhar ali efalar "bom, dia } 1 / 07 \text { eu tenho que estar com tudo pronto, então } 0 \\
\text { que eu tenho que fazer antes disso pra deixar pronto? Eu tenho que ler alguma coisa, tenho que assistir } \\
\text { alguma coisa?". Aquele esforço mental de organizar as coisas, porque não tem ninguém ali falando "olha, } \\
\text { semana que vem tem que fazer coisa tal". }\end{array}$ \\
\hline
\end{tabular}

Fonte: As autoras

\section{Terceira fase}

$\mathrm{Na}$ terceira e última fase de entrevistas, os estudantes foram questionados sobre a experiência que tiveram ao longo do semestre com a disciplina. Foi solicitado que eles falassem sobre os seus sentimentos com a finalização do curso, quais os maiores aprendizados, se houve mudança de opinião, pensamento e/ou sentimento com relação ao ensino à distância e remoto e quais abordagens e práticas educativas foram mais significativas. Foram destacadas três categorias do conteúdo das respostas.

A categoria Particularidades da disciplina destaca-se por trazer as comparações que os estudantes estabeleceram entre a disciplina em foco e as demais realizadas 


\section{Quadro 8. Temas e exemplos da categoria Sentimentos relatados}

\begin{tabular}{|c|c|}
\hline TEMAS & EXEMPLOS \\
\hline $\begin{array}{l}\text { Mobilização } \\
\text { pelo conteúdo } \\
(n=12 ; 75 \%)\end{array}$ & $\begin{array}{l}\text { "IL, } 20 \text { anos, fem: "[...] eu tava gostando muito do conteúdo e eu realmente vi uma importância no } \\
\text { conteúdo no meu voluntariado [...] parecia que eu tava vendo alguma coisa que realmente ia ser muito } \\
\text { útil para minha vida profissional, então eu acho que eu me senti realizada [...]" } \\
\text { KA, } 22 \text { anos, masc: "[...] eu também gostei dos tópicos que foram abordados, né... Como que é, é } \\
\text { como... Desenvolvimento cognitivo, é essa ideia de... Como que é, essa ideia de... Valores centrais, valores } \\
\text { periféricos, né, falar, pensar em como que o aluno aprende, achei fantástico, eu gostei bastante, aí eu fui } \\
\text { ficando, assim." }\end{array}$ \\
\hline $\begin{array}{l}\text { Motivação pela } \\
\text { diversidade de } \\
\text { metodologias } \\
(n=6 ; 37,5 \%)\end{array}$ & $\begin{array}{l}\text { NI, } 20 \text { anos, fem: "[...] foi uma forma muito democrática, todo mundo pôde ter o seu momento na dis- } \\
\text { ciplina, porque se a pessoa não gostava muito de texto, teve os vídeos, se a pessoa não gostava muito de } \\
\text { vídeo, teve os textos, e teve modalidade de Podcast, e teve modalidade que teve que ser escrita, teve } \\
\text { filme pra ver, teve atividade em grupo, individual. [...]" }\end{array}$ \\
\hline $\begin{array}{l}\text { Preocupação em } \\
\text { atrasar o fim da } \\
\text { graduação } \\
(n=6 ; 37,5 \%)\end{array}$ & $\begin{array}{l}\text { JB, } 20 \text { anos, fem: "minha motivação mesmo é que eu preciso me formar, então eu não tranquei } \\
\text { nenhuma disciplina quando passou do presencial pro virtual. [...]" } \\
\text { MB, } 23 \text { anos, fem: "[...] Eu tava terminando a graduação mesmo, né, e eu não ia parar de fazer o curso. } \\
{[. . .] \text { " }}\end{array}$ \\
\hline $\begin{array}{l}\text { Vontade de } \\
\text { retribuir a } \\
\text { dedicação da } \\
\text { professora e } \\
\text { monitores }\end{array}$ & $\begin{array}{l}\text { BB, } 28 \text { anos, masc: "[...] eu vi muito trabalho de vocês [professora e monitores], eu vi muito trabalho e } \\
\text { muita interação com a gente, eu vi muito essa busca de construção, então... Eu meio que, eu posso dizer } \\
\text { que eu fui respondendo a esse trabalho de vocês, eu fui respondendo da minha melhor forma porquê... } \\
\text { Eu acho que, eu já disse antes, que como isso foi construído de uma maneira coletiva, eu fui respondendo } \\
\text { à altura, sabe [...]" }\end{array}$ \\
\hline
\end{tabular}

$(n=5 ; 31,25 \%)$

Fonte: As autoras 
naquele semestre, argumentando que esta migração foi bem sucedida. Ao compararem o que tinham acabado de vivenciar com o que conheciam de $\mathrm{EaD}$, os participantes apontaram que não esperavam muita interação entre aluno-professor e aluno-aluno, mas que, ao longo do curso, perceberam que é possível ter uma experiência à distância bastante interativa. A empatia da docente foi uma característica que chamou a atenção dos estudantes, que a descrevem como muito humana, flexível, que se importa e busca entender cada um.

A categoria Percepções relatadas evidencia uma mudança de visão acerca do que os participantes acreditavam ser limitações dos cursos não presenciais, por perceberem que a aprendizagem não foi prejudicada e que a interação com a turma foi possível. A necessidade de ter autonomia e autorregulação para lidar com as atividades e prazos propostos foi mais uma vez destacada. A interação entre professor e aluno, tanto na elaboração de atividades que atendam à diversidade do corpo discente quanto diariamente, através da comunicação e conexão mais individualizada, fundamentos éticos da disciplina, foi mencionada com bastante frequência, bem como o olhar para o outro, proporcionado principalmente pelas atividades em grupo.

A categoria Sentimentos relatados destaca que houve grande quantidade de relatos sobre o impacto causado pelo estudo do tema "Projetos de Vida", tanto no âmbito pessoal quanto profissional, levando-os a refletir sobre os seus próprios projetos, seus valores e também em como auxiliar seus alunos na construção de valores e objetivos futuros. Concluir o curso foi significado pela maioria como uma conquista e realização, despertando sentimentos de satisfação, bemestar, felicidade, orgulho e gratidão. Uma minoria sentiu-se aliviada por ter chegado ao final e concluído o que foi proposto.

\section{DISCUSSÃO DOS RESULTADOS}

A análise das entrevistas fez emergir, a partir das percepções e sentimentos dos estudantes de licenciatura, questões importantes para a sinalização de caminhos da ERE e também de cursos presenciais e em EaD, por meio das possibilidades e dos desafios elencados.

Percebe-se, ao longo das fases de entrevistas, que as categorias advindas dos temas levantados se mantiveram com outras significações, de acordo com as mudanças de perspectivas dos participantes. $\mathrm{O}$ aprofundamento nas reflexões 


\section{Quadro 9. Temas e exemplos da categoria Particularidades da disciplina}

\begin{tabular}{|c|c|}
\hline TEMAS & EXEMPLOS \\
\hline $\begin{array}{l}\text { Comparação com } \\
\text { outras disciplinas } \\
(n=6 ; 37,5 \%)\end{array}$ & $\begin{array}{l}\text { "H0, } 22 \text { anos, masc: "[...] foi o curso do primeiro semestre de } 2020 \text { que pra mim fez a melhor fez a } \\
\text { transição e a conversão do curso pro que havia sido pensado pro ambiente físico da sala de aula, foi o que } \\
\text { melhor realizou." }\end{array}$ \\
\hline $\begin{array}{l}\text { Comparação } \\
\text { com o EaD } \\
\text { que conheciam } \\
(n=5 ; 31,25 \%)\end{array}$ & $\begin{array}{l}\text { H0, } 22 \text { anos, masc: "0 grande problema dos cursos de ensino à distância [...] em que as aulas eram } \\
\text { gravadas e que depois os alunos assistiam e tinham os fóruns de discussão [...] os alunos tinham muito } \\
\text { pouco acesso ao diálogo direto com o professor e com outros alunos então é bem desmotivador não } \\
\text { poder exercitar os conhecimentos, não poder discutir nada nem ter com quem conversar, eu senti que a } \\
\text { professora claramente desde o início mostrava como a saída interacionista era a melhor opção [...]. Até } \\
\text { com o ensino a distância ela sempre abria as aulas pra discussão, havia dinâmica de trabalho em grupo, } \\
\text { então justamente ela conseguiu mostrar na situação limite como foi a quarentena de que talvez a saída } \\
\text { socioconstrutivista, [...] ela mostrou que talvez fosse a melhor opção." }\end{array}$ \\
\hline
\end{tabular}

Empatia da

docente

responsável

$(n=5 ; 31,25 \%)$

Fonte: As autoras
MC, 21 anos, fem: "[...] acho que foi um aprendizado, que a disciplina também me fez ter justamente, pela professora ter esse olhar mais flexível, de entender mais a gente, de acompanhar caso a caso."[...] eu aprendi muito com ela, assim, ela com certeza vai ser um exemplo daqui para frente, de um tipo de professora que eu quero ser, você percebe que em toda fala, ela consegue envolver a gente, tenta tornar nós, educadores, melhores, e fazer com que a gente consiga entender os nossos alunos, conseguir ver que, de fato, cada aluno é uma escola, né, que os valores impactam muito na forma que o sujeito, que os alunos, vão lidar com algumas questões [...."

sobre a disciplina levou a um movimento metacognitivo sobre o próprio processo educacional e sobre a educação de uma forma geral. Os temas levantados também fizeram emergir o processo de autoconhecimento que foi proporcionado pelo curso e pelo momento da pandemia, levando os participantes a relatarem com mais profundidade suas emoções e sentimentos. Dessa forma, percebe-se que a manutenção das atividades acadêmicas, mesmo à distância e em tempos complexos, pôde corroborar, como já sinalizava Arruda (2020), para a manutenção de vínculos e para o fortalecimento da instituição enquanto formadora de professores dentro de uma perspectiva de atuação ética (Imbernón, 2006). 


\section{Quadro 10. Temas e exemplos da categoria Percepções relatadas}

\begin{tabular}{|c|c|}
\hline TEMAS & EXEMPLOS \\
\hline $\begin{array}{l}\text { Mudança } \\
\text { de visão sobre } \\
\text { o Ensino } \\
\text { Remoto/EaD } \\
(n=5 ; 31,25 \%)\end{array}$ & $\begin{array}{l}\text { BB, } 28 \text { anos, masc: "[...] eu acredito que pode ser com qualidade, como eu já disse: essa disciplina foi di- } \\
\text { ferente das outras, que teve esse semestre mesmo, então não vou generalizar ou idealizar o ensino EaD } \\
\text { novamente, mas o que eu entendi, quando eu concluí, é que... Pode, pode sim dar certo, pode sim você } \\
\text { ter o ensino EaD, você ter uma organização online e uma disciplina, você construir um, tipo, um caminho } \\
\text { de conhecimento de forma EaD, de forma à distância, eu tinha muito esse tabu de achar que não ia dar } \\
\text { certo [...]" }\end{array}$ \\
\hline $\begin{array}{l}\text { Necessidade } \\
\text { de autonomia e } \\
\text { autorregulação } \\
(\mathrm{n}=4 ; 25 \%)\end{array}$ & $\begin{array}{l}\text { MC, } 21 \text { anos, fem: "[...] acho que aprendi a ter mais autonomia, porque os prazos foram mais flexíveis } \\
\text { e, mesmo assim, a gente precisava ler algo, a gente precisava buscar algo pra comentar, né, a discussão na } \\
\text { aula, então mesmo com prazo mais flexível, eu precisei me organizar melhor para conseguir fazer as ati- } \\
\text { vidades a tempo de discutir aulas síncronas [...]" }\end{array}$ \\
\hline $\begin{array}{l}\text { Importância da } \\
\text { aproximação } \\
\text { entre aluno e } \\
\text { professor } \\
(n=7 ; 43,75 \%)\end{array}$ & $\begin{array}{l}\text { NI, } 20 \text { anos, fem: "[...] Acho uma coisa que fica reforçada, na verdade, para mim, éa questão do respeito } \\
\text { ao aluno: que o aluno, cada aluno, tem uma história, ele tem a sua historinha. Sempre foi muito importante } \\
\text { para mim saber a história das pessoas, mas com essa disciplina, eu acho que reforça isso: você tem que re- } \\
\text { almente ver o ser humano como um individuozinho único, assim, então... Você tem que estar muito } \\
\text { atento ao contexto que você tá dando aula, a cada um dos seus alunos, e acho que uma coisa que foi } \\
\text { muito reforçada aqui, que foi mostrado pra gente, são as formas de, é... Educar. As diferentes formas de } \\
\text { educar. [...]" }\end{array}$ \\
\hline
\end{tabular}

Trabalhos em

grupo e o olhar

para o outro

$(n=2 ; 12,5 \%)$

Fonte: As autoras
MC, 21 anos, fem: [...] Acho que também, nesse contexto de pandemia, teve aquela questão de, por exemplo, de marcar reunião, mas, às vezes, o integrante não pode, as pessoas não podem, então aprendi a ser mais flexível também, entender o lado do outro, entender que cada um tem uma condição - às vezes, na nossa casa é complicado [...] 


\section{Quadro 11. Temas e exemplos da categoria Sentimento relatados}

\begin{abstract}
TEMAS EXEMPLOS
Mobilização pelo

tema "Projetos

de Vida"

$(n=13 ; 81,25 \%)$

SV, 26 anos, fem: “[...] A parte dos projetos de vida foi... Nossa! Mudou muito a minha forma de pensar, porque é aquilo, fazendo o trabalho a gente para pra prestar atenção que às vezes a gente não tá muito com um projeto de vida. Então tá me fazendo repensar muito e também como professora, como que eu vou ser, porque a gente acaba sendo muito a referência para os nossos alunos. Que professor que eu quero ser? Me fez refletir demais."
\end{abstract}

Sentimentos

positivos por

concluir o curso

(felicidade)

orgulho/vitória)

$(n=10 ; 62,3 \%)$

Alívio por

concluir o curso

$(n=4 ; 25 \%)$

Fonte: As autoras
SV, 26 anos, fem: "[...] pra mim foi uma experiência maravilhosa e enriquecedora e eu aprendi muito, muito mais ainda com a pandemia, me fez ver outras coisas também, que eu não aprenderia talvez se não tivesse. E pra mim é isso, gratidão eterna. Marcou a minha vida."

JB, 20 anos, fem: "Eu me sinto aliviada de ter conseguido acabar, de ter dado tudo certo, de ter conseguido acompanhar. [...]"

A categoria Particularidades da disciplina, presente nas três fases de entrevistas, traz alguns aportes importantes para a migração de disciplinas para a ERE e para a formulação de cursos à distância. O primeiro ponto está nos princípios do curso e na forma como os conteúdos foram mantidos de forma alinhada à vida acadêmica, pessoal, social e profissional dos licenciandos. As estratégias utilizadas para a abordagem teórica, levaram os estudantes a perceberem que as temáticas lhes eram relevantes. Gatti (2010) evidencia a importância dos cursos de formação inicial docente resgatarem a função própria da escolarização, qual seja, ensinar o conhecimento acumulado e consolidar valores e prática coerentes com a vida em sociedade. Além disso, ao tecer relações com as demandas reais dos estudantes e da educação, assumiu-se o compromisso de colaborar para a constituição de identidades docentes comprometidas com a 
compreensão sobre a sociedade atual e com a transformação social (Imbernón, 2006).

Ainda nessa categoria, evidencia-se a importância de aplicar diversas metodologias ativas de aprendizagem, que tornaram o curso na ERE inclusivo, dando a oportunidade para que todos pudessem participar e interagir. Um dos erros mais presentes na migração para a ERE, como assinala Araújo (2020), é dedicarse apenas à instrução e não à educação, em seu sentido formativo. Os estudantes valorizaram os momentos de interação e as diferentes formas de produção de conhecimentos que foram proporcionadas ao longo do curso, levando-os a se sentirem ativos, motivados e produtores de conhecimentos (Freire, 1996), mesmo no contexto de adversidade da pandemia.

Outro ponto de destaque foi a interação entre docente, monitores e discentes. Os licenciandos evidenciaram a clareza na comunicação, os fundamentos éticos e a perspectiva humanizada adotada em todos os momentos do curso. Nesse sentido, as ações de aproximação, de escuta e de flexibilidade foram entendidas pelos participantes como uma postura empática da docente, que lhes serviu como inspiração para suas práticas. A percepção dos estudantes reitera a necessidade dos cursos superiores de se fundarem na ética, no respeito e na autonomia do educando (Freire, 1996). Fomentar uma cultura participativa deve ser um princípio balizador da formação de professores, que requer reconhecer cada licenciando com sua história, sua identidade e seus projetos de vida (Araújo, Arantes, \& Pinheiro, 2020).

Deve-se salientar, ainda, que o processo formativo envolve muito mais do que a cognição, estando-lhe inerentes as emoções e os sentimentos. Na categoria Particularidades da disciplina e na categoria Sentimentos relatados, evidenciamse sentimentos positivos projetados sobre a disciplina, a docente e os monitores. Tais sentimentos organizam as ações de continuidade da disciplina pelos licenciandos, trazendo-lhes motivação e engajamento. Assim, a migração de disciplinas para a ERE ou a construção de cursos na modalidade EaD, em especial os de formação inicial docente, precisam considerar a atuação das emoções e sentimentos que influem no equilíbrio das relações e no entendimento mútuo, levando todos os envolvidos a construírem uma percepção mais aguçada sobre si e sobre os outros (Hargreaves, 2003). Ainda considerando as mudanças exigidas pela ERE e pela EaD, faz-se necessário não apenas realizar mudanças técnicas, mas vislumbrar a complexidade do contexto e as questões emocionais presentes 
na rede de relacionamentos humanos significativos para o processo educacional (Hargreaves, 2003).

A organização da disciplina, na categoria Particularidades da disciplina, também evidencia um ponto de atenção na migração para a ERE ou para a construção de cursos em EaD. Os estudantes sinalizaram o quanto a rapidez e a organização de um ambiente virtual de aprendizagem bem estruturado apoiou o acompanhamento da disciplina. Também ressaltaram a importância do processo de escuta, a flexibilidade e a reorganização das ações de acordo com as necessidades dos estudantes.

Entre os desafios sinalizados pelos participantes, foi dado destaque à necessidade de autonomia e de autorregulação trazida pelo contexto em que estavam inseridos, tema presente nas três fases de entrevistas. A dificuldade de se organizar no momento próximo da migração do curso recebeu bastante realce na primeira entrevista, o que diminuiu na segunda e não foi mencionado na terceira entrevista. Os licenciandos relataram com frequência que, por não se deslocarem até o ambiente universitário e nem se encontrarem pessoalmente com os colegas de turma e seus professores, foi exigido deles um maior esforço para lidar com a própria rotina, seus afazeres e a urgência de organização. Esse desafio vai ao encontro do que Freire (1996) propõe ao defender a formação de sujeitos autônomos, que só será possível a partir de docentes conscientes da própria autonomia e de seu desenvolvimento.

Sentimentos como medo e insegurança estiveram presentes nas duas primeiras fases das entrevistas, quando os participantes discorreram sobre a inevitabilidade de aprender a utilizar as ferramentas digitais, gerando inseguranças, como sinalizado por Hodges et. al. (2020). Tal aspecto recebeu atenção durante o desenvolvimento do curso e aos licenciandos foi oferecido auxílio constante por parte dos monitores e da professora, como indicado no tema "Adequação às necessidades e dificuldades dos alunos", que compõe a categoria Particularidades da disciplina na segunda fase da entrevista. É provável que isso esteja relacionado com a falta de destaque dada a esses sentimentos na última fase da entrevista.

A falta de separação entre os espaços de trabalho, familiar e acadêmico foi um desafio que impactou a experiência dos licenciandos no curso, sendo mencionado nas duas primeiras fases das entrevistas. Na última fase da entrevista, por outro lado, houve um predomínio muito forte de descrições sobre sentimentos positivos a respeito da realização do curso. Referenciando a aflição, a preocupação 
e todas as mudanças provocadas pelo o contexto turbulento, os participantes explicaram que cursar a disciplina foi uma espécie de refúgio. Nesse sentido, finalizar a experiência Ihes proporcionou felicidade, orgulho, satisfação, bemestar, gratidão e até alívio.

É importante ressaltar que os participantes demonstraram, em geral, boas condições de acesso e de saúde para acompanhar a disciplina na ERE, sendo essas questões primordiais e que antecedem os desafios por eles mencionados. $\mathrm{O}$ contexto da pandemia foi vivenciado de forma singular. Os licenciandos evidenciam a preocupação com aqueles que, em situações mais vulneráveis, não têm a oportunidade de manutenção das atividades formativas, como eles tiveram.

\section{CONSIDERAÇÕES FINAIS}

No percurso deste artigo, buscamos evidenciar que, para além do uso de técnicas e da mediação tecnológica, faz-se necessário respeitar os princípios que devem nortear a formação de professores no ensino superior na migração da disciplina para a ERE. Para tanto, fez-se necessário o uso do conceito de educação remota emergencial elucidando a ideia de uma formação que corrobora tanto a constituição identitária quanto a formação do coletivo, centrada nas necessidades democráticas de nossa sociedade. $O$ caminho encontrado nesse percurso foi de levantar as percepções e sentimentos dos licenciandos ao longo do curso, os quais apontaram desafio e possibilidade para os cursos no ensino superior em diferentes modalidades, inclusive as remotas.

Embora o presente estudo apresente limitações, especialmente pelo número reduzido de participantes, acreditamos que ele fomenta importantes reflexões a respeito das iniciativas nos cursos de formação inicial docente no ensino superior, especialmente pela perspectiva de humanização, pela reconstrução de conhecimentos de forma alinhada às necessidades dos licenciandos e pelo uso de estratégias que potencializam a sua participação e consideram as relações e as questões emocionais que atuam fortemente para a constituição de uma comunidade de aprendizagem. A experiência da migração dessa disciplina mostra que, superadas dificuldades que impedem o acesso às atividades educacionais, mesmo em contexto de grande adversidade, é possível oferecer uma formação de educadores atenta e atuante em relação às demandas do mundo contemporâneo. 
Destaca-se, por fim, que a metodologia empregada na pesquisa apresentada, por meio do estudo qualitativo das percepções e sentimentos de estudantes, pode ser aplicada em outros contextos e com número maior de participantes, favorecendo a reflexão e, consequentemente, a necessária transformação da formação inicial docente no ensino superior.

\section{REFERÊNCIAS}

Araújo, U. (2020). O pandemônio escolar na pandemia. Disponível em: http://www.ulissesaraujjo.com/2020/09/24/0-pandemonio-escolar-na-pandemia/. Acesso em: jan. 2021.

Araújo, U. F., Arantes, V., \& Pinheiro, V. (2020). Projetos de vida: Fundamentos psicológicos, éticos e práticas educacionais. Summus Editorial.

Arruda, E. P. (2020). Educação Remota Emergencial: elementos para políticas públicas na educação brasileira em tempos de Covid-19. Em Rede - Revista de Educação a Distância, 1(7), p. 257-275. Disponível em: https://www.aunirede.org.br//revista/index.php/emrede/article/view/621

Azevedo, R. O. M., Ghedin, E., Silva- Forsbered, M. C., \& Gonzaga, A. M. (2012). Formação inicial de professores da educação básica no Brasil: trajetória e perspectivas. Revista Diálogo Educacional, 12(37), 997-1026.

Bardin, L. (2011). Análise de conteúdo. São Paulo: Edições 70.

Bates, T. (2015). Educar na Era Digital. Versão ABED.

Brasil (1996). Lei no 9.394, de 20 de dezembro de 1996. Estabelece as diretrizes e bases da educação nacional. Brasília: Presidência da República. Disponível em: http://portal.mec.gov.br/seesp/arquivos/pdf/lei9394_Idbn1.pdf Acesso em: 20 mar. 2020.

Brasil (2015). Ministério da Educação. Conselho Nacional de Educação. ConseIho Pleno. Resolução no 02/CP/CNE/2015. Define as Diretrizes Curriculares Nacionais para a formação inicial em nível superior (cursos de licenciatura, cursos de formação pedagógica para graduados e cursos de segunda licenciatura) e para a formação continuada. Brasília: CP/CNE/MEC. 
Brasil (2020). Ministério da Educação. Portaria no 343, de 17 de março de 2020. Dispõe sobre a substituição das aulas presenciais por aulas em meios digitais enquanto durar a situação de pandemia do novo coronavírus COVID-19. Diário Oficial da União: seção 1, Brasília, DF, ano 157, n. 53, p. 39.

Delors, J., Mufti, I. A., Amagi, I., Carneiro, R., Chung, F., Geremek, B., Gorham, W., Kornhauser, A., Manley, M., Quero, M. P., Savané, M.; Singh, K., Stavenhagen, R., Suhr, M. W., \& Nanzhao, Z (1996). Educação, um tesouro a descobrir: relatório para a UNESCO da Comissão Internacional sobre Educação para o Século XXI. Brasília: MEC-UNESCO, 2010. (Obra publicada originalmente em 1996). Disponível em: https://unesdoc.unesco.org/ark:/48223/pfo000109590_por

Freire, P. (1974/2019). Pedagogia do oprimido. 69 ed. São Paulo: Paz e Terra.

Freire, P. (1996). Pedagogia da autonomia: saberes necessários à prática educativa. 41 ed. São Paulo: Paz e Terra.

Gatti, B. (2010). Formação de professores no Brasil: características e problemas. Educação \& Sociedade, v. 31, n. 113, p. 1355-1379.

Hargreaves, A. (2003). Aprendendo a mudar: o ensino para além dos conteúdos e da padronização. Porto Alegre: Artmed.

Hodges, C., Moore, S., Lockee, Trust, T., \& Bond, A. (2020). The difference between emergency remote teaching and online learning. EDUCAUSE Review. Louisville, CO. Disponível em: https://ereducause.edu/articles/2020/3/the-difference-between-emergency-remote-teaching-and-online-learning

Imbernón, F. (2006). Formação docente e profissional: formar-se para a mudança e a incerteza. 6 ed. São Paulo: Cortez.

Marconi, M. A., Lakatos, E. M. (2004). Técnicas de pesquisa. São Paulo: Atlas.

Nóvoa, A. (2011). Tendências atuais na formação de professores: o modelo universitário e outras possibilidades de formação. Congresso Estadual Paulista sobre Formação de Professores, 11, Águas de Lindóia. Anais: Águas de Lindóia: Congresso Estadual Paulista sobre Formação de Educadores.

Pedró, F. (2020). Formación y Actualización de los Docentes en el contexto de Pandemia. La Educación Superior en Nicaragua 2020 y El Impacto de la COVID-19. Disponível em: https://www.iesalc.unesco.org/evento/foro-la-educacion-superior-en-nicaragua-2020-y-el-impacto-de-la-covid-19/ 
Piaget, J. (1979). Aprendizagem e conhecimento. Rio de Janeiro: Freitas Bartos. Pimenta, S. G., Fusari, J. C., Pedroso, C. C. A., Pinto, U. A. (2017). Os cursos de licenciatura em pedagogia: fragilidades na formação inicial do professor polivalente. Educação e Pesquisa, 43(1), 15-30. https://doi.org/10.1590/s15179702201701152815

Puig, J. M. Aprender a viver. In: Araújo, U. F., Puig, J. M., Arantes, V. A. Educação e valores: pontos e contrapontos. São Paulo: Summus, 2007.

Sommer, L. H. (2010). Formação de professores à distância: questões para o debate. Em aberto, Brasília, (84) 23, p. 17-30.

\section{BIONOTAS}

Viviane Potenza Guimarães Pinheiro. Professora Doutora da Faculdade de Educação da Universidade de São Paulo (USP). Realiza pesquisas nas áreas de psicologia moral, psicologia do desenvolvimento e educação. Coordena o Laboratório de Educação em Valores e Socioemocional (Lab_Educare).

Correo electrónico: vipinheiro@usp.br

https://orcid.org/0000-0003-4305-1089

Beattriz Guedes de Seixas. Licenciada em Química pela UERJ. Mestranda em Educação pela USP e bolsista no Programa de Pesquisa para Desenvolvimento Profissional de Professores (NAP-USP). Realiza pesquisas sobre Projetos de Vida e Formação de Professores. Monitora e professora de Química.

Correo electrónico: bguedes@usp.br

https://orcid.org/0000-0003-1924-2782 